\title{
The Impact of Entrepreneurial Training and Performance of SMEs In Ghana
}

Richard Sarfo Gyasi ${ }^{1}$, Cai Li ${ }^{1}$, Isaac Gumah Akolgo', Yvonne Owusu-Ampomah ${ }^{2}$

${ }^{1}$ School of Management Science and Engineering, Jiangsu University, 301 Xuefu Road, Zhenjiang, 212013, China, PR

2Department of Social Studies Education, University of Education, Winneba, Ghana

Corresponding Author : richbay8081@gmail.com

The research is financed by Soft Science of Zhenjiang City in Jiangsu province with Research name: Experience of Innovation-driven Evolution in Southern Jiangsu and its Enlightenment to High Level Development of Zhenjiang with Research number: RK2017008

\begin{abstract}
In developing countries such as Ghana, the economic landscape is changing, with a move from foreign direct investment to self-employment and entrepreneurship. Academics, practitioners and governments worldwide increasingly recognized the role of education and training in providing entrepreneurs with the necessary business skills and acumen to plan, set up and grow their business ideas. The main aim of the study is to investigate the impact of entrepreneurial training intervention on innovations and performance of small scale automobile businesses in Ghana. Data was collected from small scale automobile business owners and managers in Kumasi Metropolis in the Ashanti Region of Ghana. The convenient sampling method was used to select eight hundred and ninety-six (896) respondents for the study. The data was analyzed meaningfully following the appropriate protocols by categorizing and coding. The Statistical Package for Social Science (SPSS) version 21.0, SMART PLS 3.2.8 and Microsoft Excel 2007 were used in analyzing the data. The study reveals that; there is a significant relationship between entrepreneurial training interventions and performance of small scale automobile firms in Ghana.
\end{abstract}

Keywords : SMEs Performance, Absorptive Capacity, Interventions, Entrepreneurial Training, Knowledge

\section{INTRODUCTION}

This section of the study seeks to evaluate the first three hypotheses that seek to understand the relationship between entrepreneurial training and performance of the SMEs in the Ghanaian context. The chapter also seeks to explore the extent to which absorptive capacity mediate the relationship between entrepreneurial training and firm performance. It also seeks to investigate whether firm performance is influenced by absorptive capacity of their owners. As indicated in earlier sections of the study (Kithae, Nyaga, \& Kimani, 2013), assert that, entrepreneurship training has a massive impact on performance of entrepreneurs. His results attest that, constant monitoring and supervision was found pivotal to translate the skills learnt into a more practical work. Entrepreneurs may be reporting an increase in sales and profits, lack of training on how to manage their finances, general management skills, communication skills, lack of role models, absences of proper monitoring and supervision will mean that the SME 
will not grow beyond the first stage of enterprise development to the other stages and will eventually fail within its first five years of existence (Njoroge \& Gathungu, 2013).

Regarding absorptive capacity, (Lindh \& Thorgren, 2016) explains that, knowledge acquisition, knowledge assimilation and knowledge application intervenes the direct relationship that exist between entrepreneurial training interventions and SMEs performance. This is because knowledge acquisition comes from the entrepreneur's ability to identify and grasp external knowledge which is pivotal to the running of an enterprise. The ability of the entrepreneur to analyze and merge new ideas and philosophies to existing ideas and philosophies is what is termed knowledge assimilation. Knowledge application is the ability of the entrepreneur to apply the new knowledge to achieve the desired results or goals of the enterprise. (Lindh \& Thorgren, 2016), argued that, in order to achieve increased business growth, entrepreneurial training puts great emphasis on critical thinking, improving cognitive abilities on the entrepreneur's creativity and opportunity recognition. Based on this, the researcher formulated these hypotheses;

- H1: There is a significant relationship between entrepreneurial training interventions and performance of small scale automobile firms in Ghana.

- H2: SMEs absorptive capacity is significantly influenced by entrepreneurial training interventions of small scale automobile firms in Ghana.

- H3: Performance of small scale automobile firms in Ghana is significantly influenced by absorptive capacity of SME owners'.

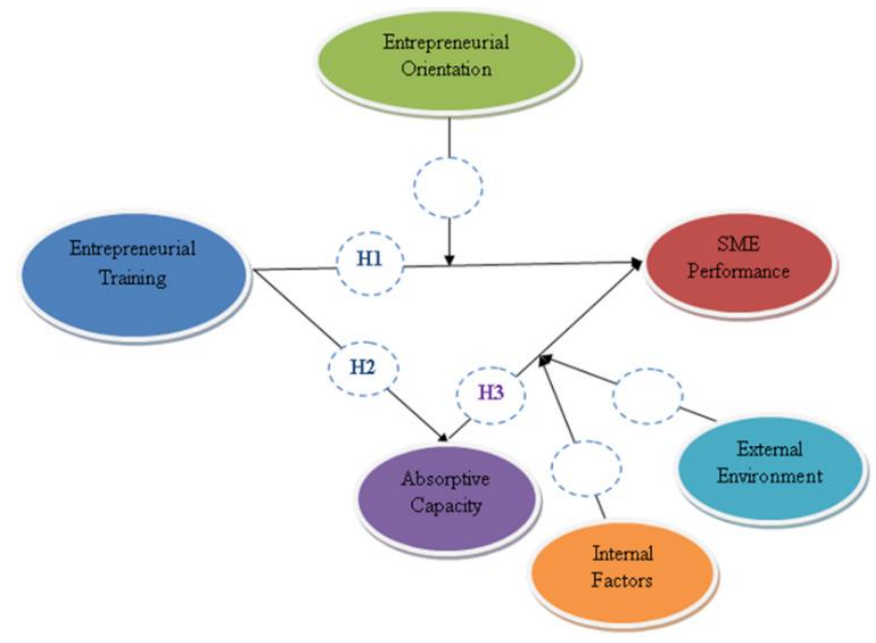

Figure 1: Conceptual Model of Analysis

Figure 1 presents the framework of the interactions between entrepreneurial training, absorptive capacity and firm performance that is investigated in the current chapter of the dissertation.

\section{METHODS AND MATERIAL}

Data for this chapter was collected as part of the entire data collected for the studies, However the only areas that is analyzed relates to the variables that affect the direct relationship between entrepreneurial training and SME's performance as well as absorptive capacity. The first relates to how the questionnaires were designed. The constructs for entrepreneurial training were deduced from previous studies which have attempted to develop constructs for entrepreneurial training interventions. The composite value of four performances was computed based on the responses. The study introduced dimensions used in measuring absorptive capacity. The combination of absorptive capacity, internal operations, worker behavior and organizational policy become more comprehensive in the study of knowledge acquisition and innovation. Thus, absorptive capacity refers not only to the behavior of employees, but also with the organization in general. This shows a more complete proposition than the 
results of which suggest that, absorptive capacity affects only the behavior of employees. The response scale for items measured was ( $5=$ Strongly Agree to $1=$ Strongly Disagree). It is necessary to recall that all the data was collected from small scale automobile business owners and managers in Kumasi Metropolis in the Ashanti Region of Ghana. The convenient sampling method was used to select eight hundred and ninety-six (896) respondents for the study. The choice of this method is for the fact that these managers and owners operate on a tight schedule and as such it will be impossible for any rigorous sampling technique. The researcher made use of the structural equation model to assess the impact of entrepreneurial training on basic SME performance. Structural equation model is a multivariate statistical analysis technique that is used to analyze structural relationships. This technique is the combination of factor analysis and multiple regression analysis, and it is used to analyze the structural relationship between measured variables and latent constructs, (Taris, 2002). This method is preferred by the researcher because it estimates the multiple and interrelated dependence in a single analysis. Again, it helped to test this study's hypothesis because it allows to test complex models for their compatibility with the data in their entirety, and allows to test specific assumptions about parameters (e. g., that they equal zero, or that they are identical to each other) for their compatibility with the data. In doing so, the variances and covariance of all the observed variables are factored systematically.

\section{Descriptive Statistics}

Respondents in this study were predominantly females with $(66.7 \%)$ while males represented a percentage of (33.3\%). The results of the study indicated a healthy working population that is youthful as the highest percentages were obtained from age groups below 41 years with (68.4\%), while the lower percentage $(7 \%)$ was obtained in the age $51+$ years. On the level of education, most of the respondents had attained a JHS/SHS certificate and they sum up to (39.8\%). Respondents with more than 15 years of working experience accounted for (6.1\%). While those who had worked within the years of 1115 were the majority with the percentage of (60.1). Correlation, Mean and Standard Deviation among the study variables are presented in table 1.

Table 1 : Correlation, Mean and Standard Deviation

\begin{tabular}{lllllll}
\hline Variable & & Mean & SD & 1 & 2 & 3 \\
\hline $\begin{array}{l}\text { 1.Entrepreneurial } \\
\text { (ET) }\end{array}$ & Training & 4.54 & 13.7 & - & & \\
2.Absorptive Capacity (AC) & 3.84 & 2.65 & $.44^{* *}$ & - & \\
3. SME $\quad$ Performance & 4.5 & 2.76 & $.49^{* *}$ & $.51^{* *}$ & - \\
(SMEP) & & & & & & \\
\hline
\end{tabular}

** Correlation is significant at the 0.01 level (2-tailed) at the diagonal

Note: $E T=$ Entrepreneurial Training, S.D=Standard Deviation, $\mathrm{AC}=$ Absorptive Capacity. Cronbach's alpha reliability coefficients ${ }^{*} \mathrm{p}<.05,{ }^{* *} \mathrm{p}<.01$.

\section{Reliability Analysis}

The t-test showed no significant differences between the small scale automobile business owners and managers in Kumasi Metropolis estimated in all the constructs which gave the impression that, the data was ready for further analysis to be done. Confirmatory factor analysis (CFA) was adopted to assess the measurement components adequacy, which also examined the reliability and validity of the constructs. Some scholars have argued that; factor loadings from .50 should be an acceptable loading. For this reason, the constructs that reported standardized factor loadings above the .50 criteria were accepted as recommended by (Hair, Hult, Ringle, Sarstedt, \& Thiele, 2017) who posited that, each item is considered a satisfactory item when item loadings are greater than 0.50 . In all, the measures of the study 
were considered as showing a reliability that is satisfactory. With regards to the convergent validity, the test showed that all the factor loadings were higher than the 0.70 suggested by (Hoyle, 1995). High average variance extracted (AVE) was demonstrated for all constructs, which provided strong evidence of convergent validity. The results of CFA, reliability, and convergent validity are shown in Table 2.

Table 2 : Confirmatory Factor Analysis

\begin{tabular}{|c|c|c|c|c|}
\hline VARIABLE & $\alpha$ & CR & AVE & $\begin{array}{l}\text { FACTOR } \\
\text { LOADING }\end{array}$ \\
\hline $\begin{array}{l}\text { Entrepreneurial } \\
\text { Training }\end{array}$ & .957 & .981 & .927 & \\
\hline ET1 & & & & .894 \\
\hline ET2 & & & & .921 \\
\hline ET3 & & & & .684 \\
\hline $\begin{array}{l}\text { Absorptive } \\
\text { Capacity }\end{array}$ & .922 & .941 & .728 & \\
\hline $\mathrm{AC} 1$ & & & & .802 \\
\hline SME & .873 & .937 & .715 & \\
\hline Performance & & & & \\
\hline SMEP1 & & & & .854 \\
\hline SMEP2 & & & & .821 \\
\hline SMEP3 & & & & .850 \\
\hline SMEP4 & & & & .802 \\
\hline
\end{tabular}

\section{Goodness of Fit}

The goodness of fit of a statistical model describes how well it fits a set of observations. Measures of goodness of fit typically summarize the discrepancy between observed values and the values expected under the model in question. Model fit and quality indices were used for modifying the model to be of good fit to the data. For us to be able to ascertain the direct positive effects of the variables, we conducted a path analysis. The following indices; Chi-square, $X^{2}$, Normed Fit Index (NFI), comparative Fit Index (CFI), and Root Mean Square Error of Approximation (RMSEA) was applied. The model fits the study with the various indices when the CFI values range between 0 and 1 and are unaffected by sample size (Byrne, 1995). NFI and CFI values greater than .90 indicate a good fit of the model to the data (L.-T. Hu \& Bentler, 1995), whereas values greater than .95 indicate an excellent fit (L.-T. Hu \& Bentler, 1995). In addition, the Root Mean Squared Error of Approximation (RMSEA), and the 90\% RMSEA confidence interval (CI). Values close to .06 for the RMSEA are indicative of an adequate model fit (L. t. Hu \& Bentler, 1999). The issue of chi-square has been debated. Traditionally, it has been argued that nonsignificance of chi-square should be met; however, as chi-square indices are inflated by sample sizes and model complexity (number of degrees of freedom), they are more likely to be significant when larger sample sizes are used and when the model has a high degree of complexity (Brown, 2014). Therefore, in this work, chi-square statistics are interpreted with caution.

\section{Confirmatory factor analysis (CFA)}

CFA is a statistical technique used to verify the factor structure of a set of observed variables. CFA allowed the researcher to test the hypothesis that; a relationship between the observed variables and their underlying latent construct(s) exists. Knowledge of the theory and empirical research, postulates the relationship pattern a priori and then tests the hypothesis statistically that, a relationship between observed variables and their underlying latent constructs exists. We performed CFA to confirm the validity of entrepreneurial training, absorptive capacity and SME performance scales. Based on the results of the CFA, we then computed variables for use in subsequent analyses. We used a full structural equation model to address our main research objective. Finally, we present computed factor scores and their correlations with affect variables to more fully understand the relationships between entrepreneurial training, absorptive capacity and SME performance. All of the analyses were performed using SMART PLS 3.2.8 software. The model produced the following indices which showed a good 
fit. Both entrepreneurial training and SME performance were treated as second order constructs obtained the following fit indices. There was $(\chi 2=1138.516, \quad \mathrm{df}=407, \quad \chi 2 / \mathrm{df}=2.797, \quad \mathrm{TLI}=.957$, $\mathrm{CFI}=.986, \mathrm{GFI}=.961, \mathrm{IFI}=.977, \mathrm{RMSEA}=.048$.

\section{Goodness of Fit}

The goodness of fit of a statistical model describes how well it fits a set of observations. Measures of goodness of fit typically summarize the discrepancy between observed values and the values expected under the model in question. Model fit and quality indices were used for modifying the model to be of good fit to the data. For us to be able to ascertain the direct positive effects of the variables, we conducted a path analysis. The following indices; Chi-square, $X^{2}$, Normed Fit Index (NFI), comparative Fit Index (CFI), and Root Mean Square Error of Approximation (RMSEA) was applied. The model fits the study with the various indices when the CFI values range

\section{Confirmatory factor analysis (CFA)}

between 0 and 1 and are unaffected by sample size (Byrne, 1995). NFI and CFI values greater than .90 indicate a good fit of the model to the data (L.-T. Hu \& Bentler, 1995), whereas values greater than .95 indicate an excellent fit (L.-T. Hu \& Bentler, 1995). In addition, the Root Mean Squared Error of Approximation (RMSEA), and the 90\% RMSEA confidence interval (CI). Values close to .06 for the RMSEA are indicative of an adequate model fit (L. t. Hu \& Bentler, 1999). The issue of chi-square has been debated. Traditionally, it has been argued that nonsignificance of chi-square should be met; however, as chi-square indices are inflated by sample sizes and model complexity (number of degrees of freedom), they are more likely to be significant when larger sample sizes are used and when the model has a high degree of complexity (Brown, 2014). Therefore, in this work, chi-square statistics are interpreted with caution.

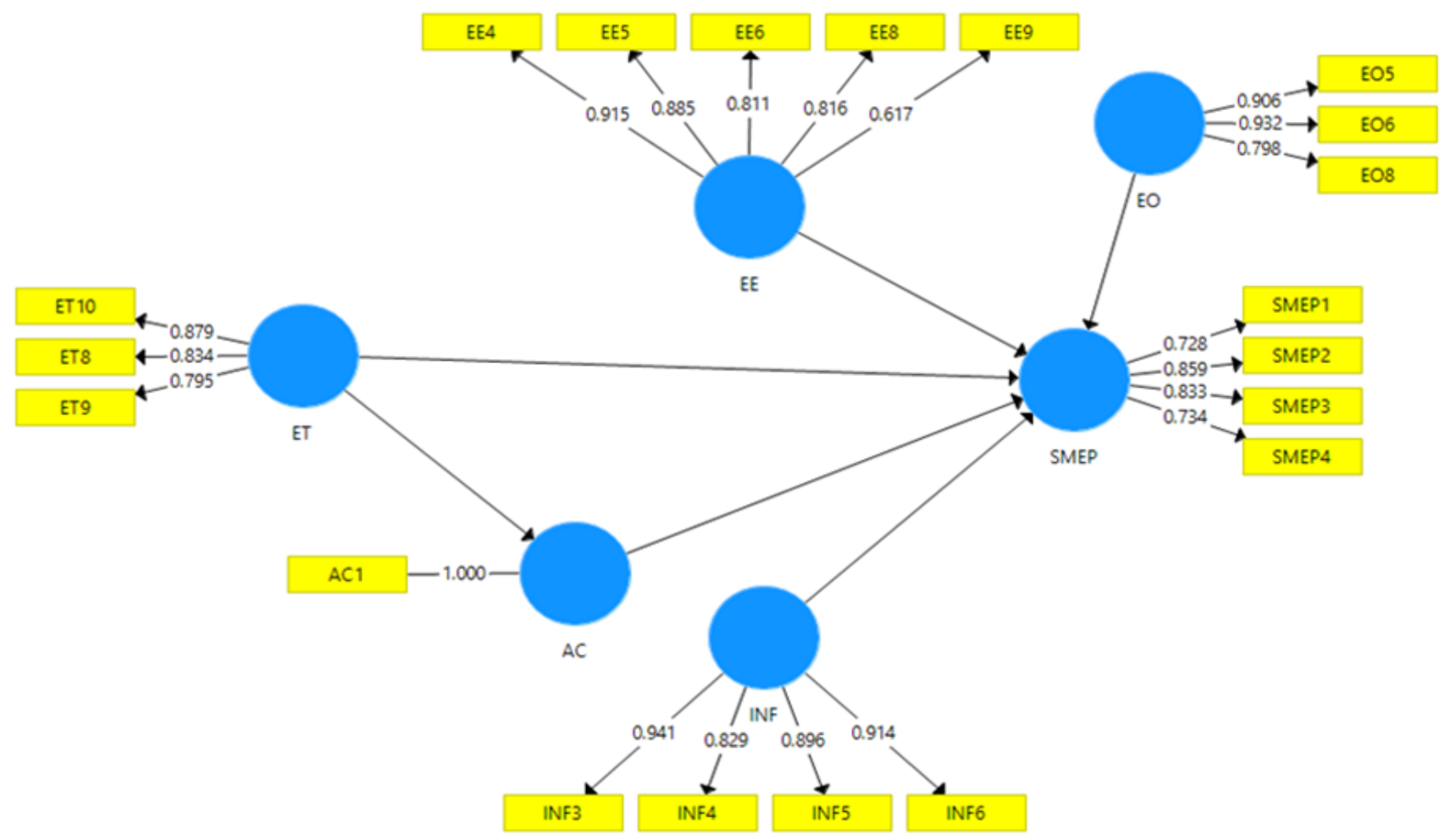

Figure 2 : Second order Confirmatory Factor Analysis of Entrepreneurial training, absorptive capacity and SME performance 


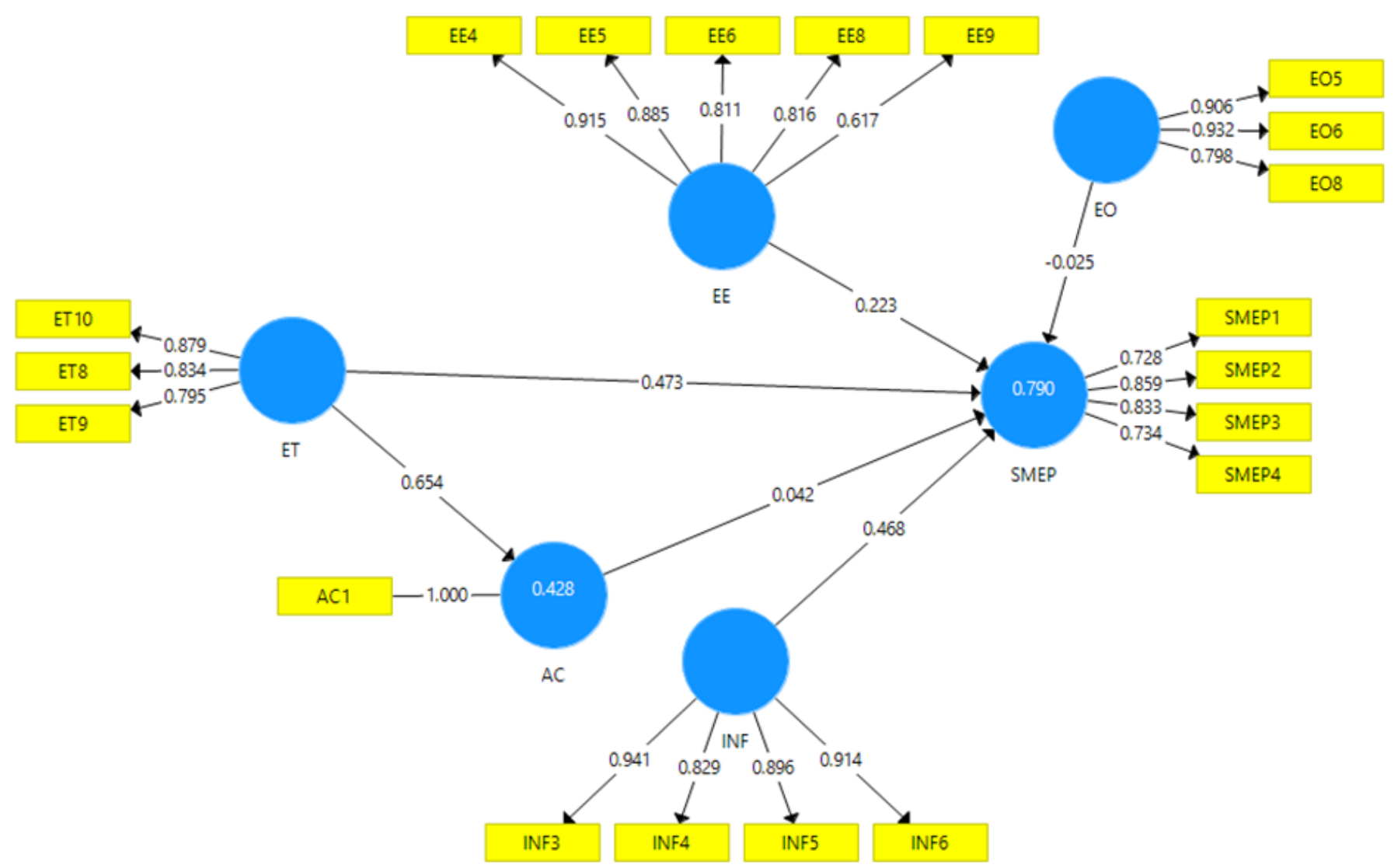

Figure 3 : Path Analysis of the Moderated Model

CFA is a statistical technique used to verify the factor structure of a set of observed variables. CFA allowed the researcher to test the hypothesis that; a relationship between the observed variables and their underlying latent construct(s) exists. Knowledge of the theory and empirical research, postulates the relationship pattern a priori and then tests the hypothesis statistically that, a relationship between observed variables and their underlying latent constructs exists. We performed CFA to confirm the validity of entrepreneurial training, absorptive capacity and SME performance scales. Based on the results of the CFA, we then computed variables for use in subsequent analyses. We used a full structural equation model to address our main research objective. Finally, we present computed factor scores and their correlations with affect variables to more fully understand the relationships between entrepreneurial training, absorptive capacity and SME performance. All of the analyses were performed using SMART PLS 3.2.8 software. The model produced the following indices which showed a good fit. Both entrepreneurial training and SME performance were treated as second order constructs obtained the following fit indices. There was $(\chi 2=1138.516, \quad \mathrm{df}=407, \quad \chi 2 / \mathrm{df}=2.797, \quad \mathrm{TLI}=.957$, $\mathrm{CFI}=.986, \mathrm{GFI}=.961, \mathrm{IFI}=.977, \mathrm{RMSEA}=.048$.

\section{Mediated Structural Model of Absorptive Capacity}

Subsequently, the mediating effect of absorptive capacity in the interaction between entrepreneurial training and SME performance was conducted using SMART PLS 3.2.8. The aim was to test whether there was a partial or full mediating effect of absorptive capacity on the relationship. A full mediating effect indicates that, without absorptive capacity there will be no relationship between entrepreneurial training and SME's performance. On the other hand, where an existing relationship is interrupted by the mediating factor, then it can be concluded that there is a partial 
mediation among the variables. The initial models lacked the adequacy to meet the required threshold, for instance, RMSEA $=0.8, \chi 2=4.06$. Assessment of the modification indices of the estimates suggested some of the constructs that should be co-vary to increase significantly the indices. The co-variance of the suggested residuals helped to significantly improve the model than the initial model. The final model showed adequacy indication of a good fit for the data. The fit indices of the final measurement model were $\mathrm{NFI}=.936, \mathrm{CFI}=.966, \mathrm{TLI}=.962, \mathrm{RFI}=.948, \mathrm{IFI}=.966$, $\chi 2=629.990, \mathrm{df}=312 \chi 2 / \mathrm{df}=2.019, \mathrm{RMSEA}=.05$

Table 3: Summary of Path Analysis of the Model

\begin{tabular}{lllrrrr}
\hline Parameter & & & Estimate & Lower & Upper & P \\
\hline SMEP & $<---$ & ET & 0.090 & -.028 & .207 & .135 \\
AC & $<---$ & ET & 0.728 & .810 & 1.023 & .000 \\
SMEP & $<---$ & AC & .051 & .903 & 1.123 & .001 \\
\hline
\end{tabular}

The analysis in the diagram presents the key indications of the acceptance of each of the three hypotheses that were presented in earlier sections of the study. Firstly, the path coefficient value of 0.090 suggests that the influence of entrepreneurial training interventions on the performance of SMEs is positive and statistically significant at $95 \%$ confidence interval. The require $\mathrm{p}$ value is 0.028 which is less than the 0.05 threshold. Establishing the mediating effect of absorptive capacity is evident in the fact that, as entrepreneurial training interventions moves through absorptive capacity to the performance of SMEs, there is an alteration of the path coefficient value from 0.090 to 0.051 . This implies that, the mediating role is not absolute but only partial. With that in mind, it is possible to conclude that, there is a significant relationship between entrepreneurial training interventions and performance of small scale automobile firms in Ghana. It is also valid to suggest that SMEs absorptive capacity is significantly influenced by entrepreneurial training interventions of small scale automobile firms in Ghana.

\section{III.CONCLUSION}

The analysis of this research sought to establish the factors that sustain automobile clusters in Ghana regarding their survival. In Ghana most automobile competitive impact in their localized clusters dotted around the country. The largest and the most vibrant of these automobile clusters is the one in the Ashanti Region of Ghana where this research has taken place. As most of these firms faces imminent collapse due to

poor management, the findings of this research provides a key arsenal to understanding the dynamics of growth and performance enhancement that is urgently needed to support effective development. The findings suggest that; it is key for these entities to focus on entrepreneurial training. It will equip them with the requisite emotional and specialized capacity to be innovative and drive productivity and other positive organization outcomes. Also critical in this venture is the role of absorptive capacity of the firm and its staff. Thus, the level of knowledge and experience of the organization have positive impact on product innovation. This finding agrees with several initial findings which observed that, a higher absorptive capacity of a firm will ultimately result in high innovation performance. Also this finding agrees with (Limaj \& Bernroider, 2019) who emphasized on the importance of capability in the use of external knowledge and thus, a firm's innovation performance is influenced by absorptive capacity. Again, this particular finding supports an earlier research by (Boateng, Owusu-Bempah, \& Ansong, 2018) who 
concluded that having regular interactions with external new knowledge promotes absorptive capacity of a firm. Any organization that deploys its resources to take advantage of the opportunities from entrepreneurial training is most likely to obtain maximum benefit from the opportunities it creates.

\section{REFERENCES}

[1]. Boateng, R., Owusu-Bempah, E., \& Ansong, E. (2018). An Absorptive Capacity Perspective of Organizational Learning Through Social Media: Evidence From the Ghanaian Fashion Industry Evaluating Media Richness in Organizational Learning (pp. 49-81): IGI Global.

[2]. Brown, T. A. (2014). Confirmatory factor analysis for applied research: Guilford Publications.

[3]. Byrne, B. M. (1995). One application of structural equation modeling from two perspectives: Exploring the EQS and LISREL strategies.

[4]. Hair, J. F., Hult, G. T. M., Ringle, C. M., Sarstedt, M., \& Thiele, K. O. (2017). Mirror, mirror on the wall: A comparative evaluation of composite-based structural equation modeling methods. Journal of the Academy of marketing Science, 45(5), 616-632.

[5]. Hoyle, R. H. (1995). The structural equation modeling approach: Basic concepts and fundamental issues.

[6]. Hu, L.-T., \& Bentler, P. M. (1995). Evaluating model fit.

[7]. Hu, L. t., \& Bentler, P. M. (1999). Cutoff criteria for fit indexes in covariance structure analysis: Conventional criteria versus new alternatives. Structural equation modeling: a multidisciplinary journal, 6(1), 1-55.

[8]. Kithae, P. P., Nyaga, J. G., \& Kimani, J. G. (2013). Role of microfinance factors on the sustainability of women managed micro and small enterprises (MSEs) in Kenya. International NGO Journal, 8(4), 94-99.

[9]. Limaj, E., \& Bernroider, E. W. (2019). The roles of absorptive capacity and cultural balance for exploratory and exploitative innovation in SMEs. Journal of Business Research, 94, 137153.

[10]. Lindh, I., \& Thorgren, S. (2016). Critical event recognition: An extended view of reflective learning. Management learning, 47(5), 525-542.

[11]. Njoroge, C. W., \& Gathungu, J. M. (2013). The effect of entrepreneurial education and training on development of small and medium size enterprises in Githunguri District-Kenya. International Journal of Education and research, 1(8), 1-22.

[12]. Taris, T. (2002). BM Byrne, Structural equation modeling with AMOS: Basic concepts, applications, and programming Mahwah NJ: Lawrence Erlbaum, 2001 0-8058-3322-6. European Journal of Work and Organizational Psychology, 11, 243-246.

\section{Cite this article as :}

Richard Sarfo Gyasi, Cai Li, Isaac Gumah Akolgo, Yvonne Owusu-Ampomah, "The Impact of Entrepreneurial Training and Performance of SMES In Ghana", International Journal of Scientific Research in Science and Technology (IJSRST), Online ISSN : 2395-602X, Print ISSN : 2395-6011, Volume 7 Issue 2, pp. 126-134, March-April 2020. Available at doi : https://doi.org/10.32628/IJSRST207215 Journal URL : http://ijsrst.com/IJSRST207215 